\title{
Pathophysiology of Alloimmunization
}

\author{
Rubiraida Molina-Aguilar ${ }^{\mathrm{a}-\mathrm{c}}$ Soledad Gómez-Ruiz ${ }^{\mathrm{a}} \quad$ Jorge Vela-Ojeda ${ }^{\mathrm{a}-\mathrm{c}}$ \\ Laura Arcelia Montiel-Cervantes ${ }^{\mathrm{a}-\mathrm{c}}$ Elba Reyes-Maldonado ${ }^{\mathrm{a}}$ \\ ${ }^{a}$ Morphology Department, Escuela Nacional de Ciencias Biológicas, Instituto Politécnico Nacional, Mexico City, \\ Mexico; ${ }^{b}$ Hematology Department, UMAE, Hospital de Especialidades Centro Médico Nacional La Raza, Instituto \\ Mexicano del Seguro Social, Mexico City, Mexico; ${ }^{\top}$ Translational Medicine Research Unit in Hemato-Oncological \\ Diseases, UMAE, Hospital de Especialidades Centro Médico Nacional La Raza, Instituto Mexicano del Seguro Social, \\ Mexico City, Mexico
}

\section{Keywords}

B lymphocytes · Transfusion · Alloantibodies .

Alloimmunization $\cdot$ Regulatory lymphocytes

\begin{abstract}
Introduction: Alloimmunization is caused by exposure to erythrocytes from a donor that expresses blood group antigens other than those of the recipient and is related to processes that alter the balance of the immune system. Knowing the pathophysiology of alloimmunization process is essential to understand clinical complications associated with this process. Patients and Methods: From October 2016 to April 2017, irregular antibody screening was performed in 1,434 polytransfused (compatible with the $A B O$ and $D$ system) patients by means of agglutination techniques using erythrocytes of a known phenotype of 44 patients with a positive alloantibody screening. Non-alloimmunized (control) subjects were matched for age, gender, pathology, and treatment group with alloimmunized patients. The subsets of $B, T$, and Treg lymphocytes were determined by flow cytometry. Results: The results of screening for alloantibodies in patients by specificity of antibodies were as follows: nonspecific (30\%), followed by anti-Di ${ }^{\mathrm{a}}(13 \%)$, anti-e (9\%), anti-S (9\%), anti-I (7\%), anti-K (7\%), and anti-P (7\%). A lower percentage of CD4+ T lymphocytes and an increase of CD8+ T lymphocytes were observed in alloimmunized patients, as well as a low CD4/CD8 ratio (0.7 vs. $1.6, p=0.003)$, a higher percentage of $\mathrm{B}$ lymphocytes versus the control group (30 vs. $20 \%, p=0.003)$, and a decrease of Treg CD4+ lymphocytes versus the control group ( 3 vs. 12 cells $/ \mu \mathrm{L}, p=0.043$ ).
\end{abstract}


for the development of alloimmunization is exposure to the donor erythrocyte antigens that are absent in the recipient; these antigens have the ability to initiate the formation of antibodies against erythrocytes resulting in transfusion reactions that are potentially serious [6-8]. This process represents an important complication in patients with repeated transfusions, since the levels of alloantibodies can be reduced over time (evanescence) and overlooked in future determinations, although this does not preclude the probability of suffering severe transfusion reactions [9].

Studies suggest that alloimmunization is related to onco-hematological disease and organ transplantation, because these events alter the equilibrium of the immune system [10]. The analysis of subpopulations of CD4+ and CD8+ lymphocytes in murine models concluded that alloimmunization requires depletion of CD4+ lymphocytes, but not of CD8+ lymphocytes [11].

In murine models with neonatal alloimmunization, an increase in CD8+ CD25+ regulatory $\mathrm{T}$ lymphocytes has been described, with an increase in the production of IL10 and IFN- $\alpha$ [12]. In patients with thalassemia alloimmunized after repeated transfusions, an increase in memory B lymphocytes (CD19+, CD38+) has been observed in comparison with non-alloimmunized patients, suggesting an important alteration of the immune system induced by erythrocyte antigens [13].

As far as the authors know, there are no reports in humans that describe the immunological changes associated with the process of alloimmunization to erythrocyte antigens. Therefore, in the present study we determined T and B lymphocyte subpopulations, as well as regulatory T lymphocytes (Treg) in patients with different hematological disorders exposed to multiple transfusions of erythrocyte concentrates (EC) and who developed alloantibodies against $\mathrm{RBC}$ of the donor; lymphocyte subsets were compared with patients in the same conditions (hematological disorder, age, sex, polytransfusion) who did not develop anti-erythrocyte alloantibody.

\section{Material and Methods}

The present study included adult patients with different hematological disorders. All patients were tested for alloantibody determinations and T, B, and Treg lymphocytes characterization from samples obtained for routine studies.

\section{Patients and Donors}

A cross-sectional cohort study was performed with recurrently transfused patients at the hematology service of the "Hospital de Alta Especialidad Dr. Antonio Fraga Mouret, Centro Médico Nacional La Raza, Instituto Mexicano del Seguro Social.” The study included all patients attended at this center from October 2016 to April 2017. Patients with hemolytic anemia (HA), myelodysplastic syndrome (MDS), multiple myeloma (MM), immune thrombocytopenic purpura (ITP), chronic myeloid leukemia (CML), and acute leukemia (AL) were included; each group consisted of 239 patients (total 1,434 patients). Patients with HIV and other viral infections were excluded from the study.

Patients with a previous report in the medical record of alloantibodies and patients with positive screening for alloantibodies according to agglutination techniques during at least two separate determinations were included. Patients who did not report a previous test in the medical record of alloantibodies and with negative screening for alloantibodies by agglutination techniques during at least two separate determinations were selected as negative controls. The control group was paired with positive patients by age, gender, pathology, and treatment group. Determinations of alloantibodies and lymphocyte subsets were performed simultaneously, immediately after the collection of samples. Clinical information was obtained from the transfusion medical records of the study center.

\section{RBCs Alloantibody Screened}

Samples were analyzed to identify the detected alloantibodies using the 10-cell panel of the "Centro Médico Nacional Siglo XXI, Instituto Mexicano del Seguro Social." The institutional code panels used were as follows: VI-2016 (03/09/16-14/10/16); VII-2016 (15/10/16-25/11/16); VIII (26/11/16-06/01/17);I-2017 (07/01/1717/02/17), and II-2017 (18/02/17-05/05/17).

These cells constitute a standard panel with known phenotype provided by the Instituto Mexicano del Seguro Social and are used for alloantibody screening. Agglutination tests were done at three temperatures: room temperature, incubation at $7^{\circ} \mathrm{C}$, incubation at $37^{\circ} \mathrm{C}$, and in Coombs serum. The criteria for antibody specificity were based on the recommendations of AABB. Plasma of each patient was analyzed in duplicate and confirmed 1 month later for patients with positive screening.

\section{Flow Cytometry Acquisition and Analysis of Lymphocyte}

Subsets

Optimal concentrations of directly conjugated (FITC, PE, Per$\mathrm{CP}$, or APC) monoclonal antibodies were added to $100 \mu \mathrm{L}$ of whole blood. The mixture was incubated for $20 \mathrm{~min}$ at room temperature $\left(20-25^{\circ} \mathrm{C}\right)$ in the dark. RBC lysis was performed using FACS Lysing Solution (Becton-Dickinson, San Jose, CA, USA), according to manufacturer's instructions. Stained cells were washed twice and resuspended in phosphate-buffered saline (PBS). The following monoclonal antibodies were used, conjugated to one of the four fluorochromes fluorescein isothiocyanate (FITC), phycoerythrin $(\mathrm{PE})$, peridinin chlorophyll protein reagent $(\mathrm{PerCP})$, and allophycocyanin (APC). Anti-CD45 APC, anti-CD4 FITC, and anti-CD3 PerCP were used to stain CD4+ T cells. To identify CD8+ T cells, the antibodies anti-CD45 APC, anti-CD3 PerCP, and anti-CD8 PE were used. Anti-CD19 PE was used to stain B lymphocytes. AntiCD4 FITC, anti-Fox P3 PE, and anti-CD25 APC were used for identification of regulatory CD4+ lymphocytes (Treg CD4) or anti-CD8 PerCP, anti-Fox P3 PE, and anti-CD25 APC were used for identification of regulatory CD8+ lymphocytes (Treg CD8). The samples of patients were acquired by BD FACS Calibur flow cytometry (BD Biosciences, San Diego, CA, USA) and analyzed by CellQuest Pro software.

\section{Statistical Analysis}

The Kolmogorov-Smirnov tests were used to evaluate the normality of the distributions. The Mann-Whitney U test was used to analyze the differences between the two groups of patients. Statistical analysis was performed using GraphPad Prism 6.0 (GraphPad Software, San Diego, CA, USA) and SPSS for Windows (SPSS Inc., Chicago, IL, USA). Statistical significance was considered at $p \leq 0.05$. 
Table 1. Characteristics of alloimmunized and non-alloimmunized patients by hematological disease, specificity of alloantibody, and CD4/CD8 ratio

\begin{tabular}{|c|c|c|c|c|c|c|c|c|c|c|c|}
\hline Hematological disease & $\begin{array}{l}\text { Non-allo- } \\
\text { immunized } \\
(n=44), \\
\%(n)\end{array}$ & $\begin{array}{l}\text { Allo- } \\
\text { immunized } \\
(n=44), \\
\%(n)\end{array}$ & $\begin{array}{l}\text { Age, years } \\
\text { [range] }\end{array}$ & $\begin{array}{l}\text { Male, } \\
n\end{array}$ & $\begin{array}{l}\text { Female, } \\
n\end{array}$ & AlloAb identify & $n$ & $\begin{array}{l}\text { Pre-allo- } \\
\text { immunized } \\
(n=17)\end{array}$ & Ratio CD4/CD8 & $\begin{array}{l}\text { Non-allo- } \\
\text { immunized } \\
\text { previously } \\
(n=27)\end{array}$ & Ratio CD4/CD8 \\
\hline \multirow[t]{8}{*}{ HA } & $50.0(22)$ & $50.0(22)$ & $58[30-73]$ & 9 & 13 & IgG autoantibody & 10 & $\begin{array}{l}4 \text { (2 Anti-I; } \\
1 \text { Anti-c; } \\
1 \text { auto anti-RH) }\end{array}$ & 0.3 & 6 & 1.0 \\
\hline & & & & & & Anti-P & 3 & - & - & 3 & 0.8 \\
\hline & & & & & & Anti-S & 2 & 2 auto anti-RH & 0.6 & - & - \\
\hline & & & & & & Anti-Jk ${ }^{\mathrm{b}}$ & 2 & 2 auto anti-RH & 0.3 & - & - \\
\hline & & & & & & Anti-e & 2 & 1 anti-s & 0.6 & 1 & 0.6 \\
\hline & & & & & & Anti-I & 1 & Anti-I & 1.5 & - & - \\
\hline & & & & & & Anti-E & 1 & Anti-c & 0.4 & - & - \\
\hline & & & & & & Anti-e+Fy ${ }^{\mathrm{a}}$ & 1 & - & - & 1 & $3.3^{1}$ \\
\hline \multirow[t]{6}{*}{ MDS } & $27.0(12)$ & $27.0(12)$ & $58[38-83]$ & 6 & 6 & IgG autoantibody & 1 & - & - & 1 & 0.3 \\
\hline & & & & & & Anti-S & 2 & $\begin{array}{l}2 \text { IgG auto- } \\
\text { antibody }\end{array}$ & 0.5 & - & - \\
\hline & & & & & & Anti-K1 & 2 & - & - & 2 & 0.8 \\
\hline & & & & & & Anti-I & 2 & - & - & 2 & 1.0 \\
\hline & & & & & & Anti-Di ${ }^{a}$ & 4 & $\begin{array}{l}3 \text { ( } 2 \text { anti-E; } \\
1 \text { anti-C+e) }\end{array}$ & $1.5^{1}$ & 1 & 1.0 \\
\hline & & & & & & Anti-e+Jk ${ }^{\mathrm{a}}$ & 1 & - & - & 1 & 0.9 \\
\hline \multirow[t]{3}{*}{ MM } & $11.0(5)$ & $11.0(5)$ & 56 [54-63] & 3 & 2 & IgG autoantibody & 3 & - & - & 3 & 0.9 \\
\hline & & & & & & Anti-K1 & 1 & - & - & 1 & 0.8 \\
\hline & & & & & & Anti-D & 1 & - & - & 1 & 0.8 \\
\hline \multirow[t]{2}{*}{$\begin{array}{l}\text { ITP (immune } \\
\text { thrombocytopenia) }\end{array}$} & $7.0(3)$ & $7.0(3)$ & 44 [24-55] & 0 & 3 & Anti-Di ${ }^{\mathrm{a}}$ & 2 & - & - & 2 & 0.6 \\
\hline & & & & & & Anti-c & 1 & $\begin{array}{l}1 \mathrm{IgG} \text { auto- } \\
\text { antibody }\end{array}$ & 0.9 & - & - \\
\hline \multirow{2}{*}{$\begin{array}{l}\mathrm{CML} \text { (chronic myeloid } \\
\text { leukemia) }\end{array}$} & $5.0(2)$ & $5.0(2)$ & 60 [54-65] & 0 & 2 & Anti-C & 1 & - & - & 1 & 0.6 \\
\hline & & & & & & Anti-M & 1 & & & 1 & 0.5 \\
\hline $\begin{array}{l}\text { EC transfusions } \\
\text { previously }\end{array}$ & $21[1-38]$ & $12[1-78]$ & & & & Global ratio & & & $0.8[0.2-2.2]$ & & $1.0[0.3-3.3]$ \\
\hline
\end{tabular}

Ranges are given in square brackets. HA, hemolytic anemia; MDS, myelodysplastic syndrome; MM, multiple myeloma; ITP, immune thrombocytopenia; CML, chronic myeloid leukemia; EC, erythrocyte concentrates. ${ }^{1}$ Patients with data outlier.

\section{Results}

Alloantibody screening was performed in 1,434 patients from October 2016 to April 2017. The results of 44 hematologic patients $(3.1 \%)$ with positive alloantibody screening were analyzed and compared with the control group that included 44 patients matched for age, gender, pathology, and treatment group (patients with negative alloantibody screening, verified by self-labeling and negative direct Coombs).

Distribution of patients according to hematological diagnosis, specificity of alloantibodies, and other clinical data are presented in Table 1 . The patients had a median age of 55 years (24-83 years), HA (membranopathy and autoimmune) (50\%) was the most common pathology for which patients presented alloimmunization, followed by MDS (27\%), MM (11\%), ITP (7\%), and CML (5\%). According to medical records, patients had a stable and controlled state of their hematologic disease. Previous to determination of alloantibodies and lymphocyte subsets, the group of alloimmunized patients received between 1 and 78 (median, 12) transfusions of EC (compatible with the $\mathrm{ABO}$ and $\mathrm{D}$ system), while the control group received between 1 and 38 (median, 21) transfusions of EC. Antibody tests were performed at 11-127 weeks after transfusion. The antibodies most frequently identified were nonspecific $(30 \%)$, followed by anti- $\mathrm{Di}^{\mathrm{a}}(13 \%)$, anti-e (9\%), anti-S (9\%), anti-I (7\%), anti-K (7\%), and anti-P (7\%). 
Fig. 1. Dot plots showing strategy of acquisition for lymphocyte subsets. a Selection of lymphocyte region for analysis of coexpression patterns of antigens characteristic of lymphocyte subtypes. The populations of classified lymphocytes are shown in the following dot plots: b B lymphocytes (CD19+); c CD8+ T lymphocytes; d CD4+ T lymphocytes. e Region selection of total CD8+ T lymphocytes for coexpression analysis of antigen characteristic of Treg lymphocytes (CD8+) (f). g Region selection of total CD4+ T lymphocytes for coexpression analysis of antigen characteristic of Treg lymphocytes (CD4+) (h).
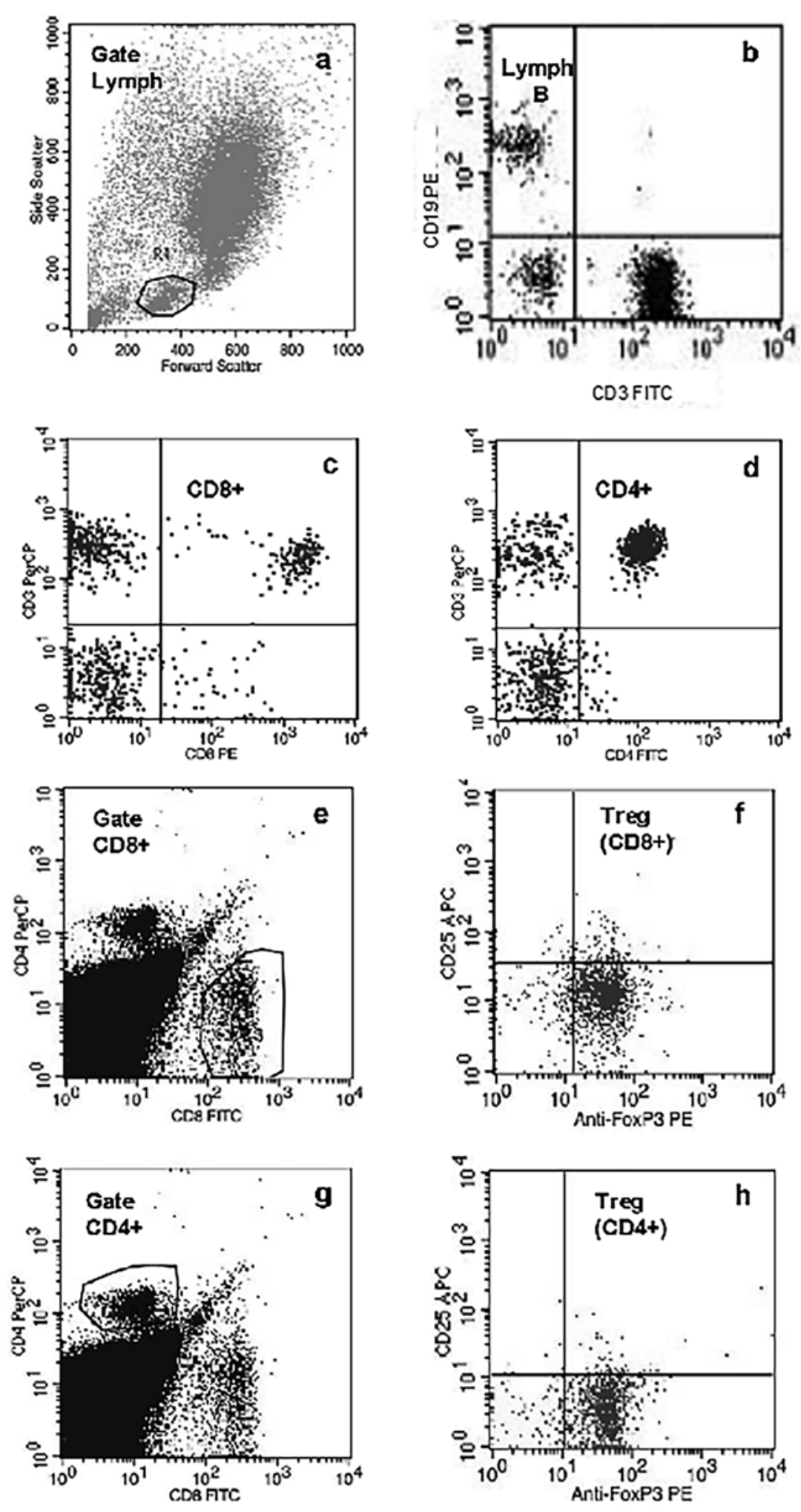

No differences were observed between alloimmunized versus non-alloimmunized patients in terms of routine hematological parameters such as white blood cell counts 5,490 cells/ $\mu \mathrm{L}(3,770-6,570)$ versus 6,610 cells/ $\mu \mathrm{L}(3,850-8,625)$, respectively; total lymphocytes counts 1,410 cells $/ \mu \mathrm{L}(840-1,850)$ versus 1,835 cells $/ \mu \mathrm{L}$ $(1,140-2,525)$, respectively; hemoglobin $11.8 \mathrm{~g} / \mathrm{dL}(9.2-$ 13.6) versus $13.8 \mathrm{~g} / \mathrm{dL}(11.3-14.9)$, respectively; and platelets count $16610^{3} / \mu \mathrm{L}(98-247)$ versus $19410^{3} / \mu \mathrm{L}$ (68-248), respectively. 

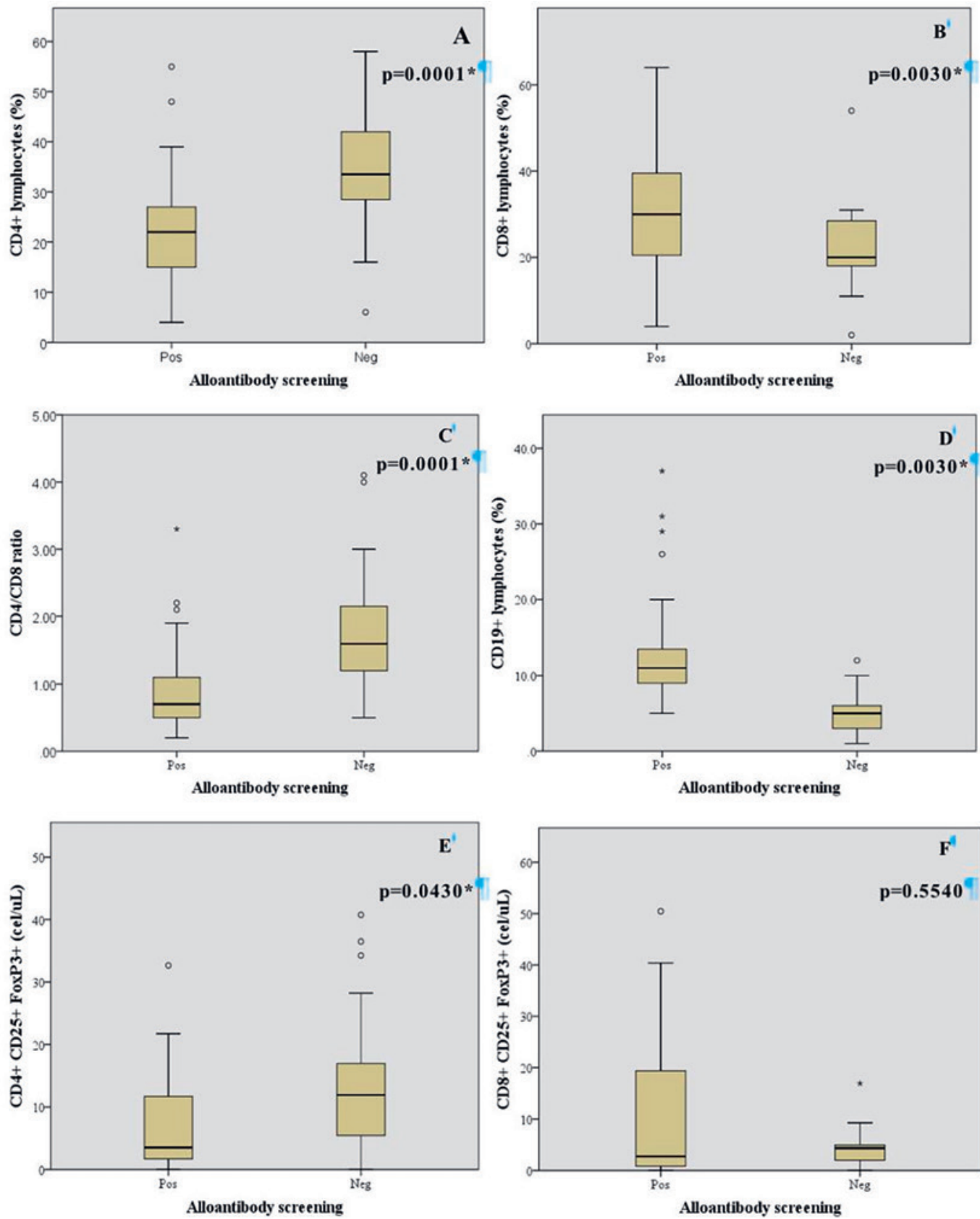

Fig. 2. Comparison between lymphocyte subsets in patients with and without anti-erythrocyte alloantibodies. Percentage comparison of: A CD4+ lymphocytes in patients with and without alloantibodies ( 22 vs. $34 \%, p=0.0001 *$ ). B CD $8+$ lymphocytes in patients with and without alloantibodies (30 vs. $20 \%, p=0.0030^{*}$ ). C Proportion of CD4+/CD8+ lymphocytes (ratio) in patients with and without alloantibodies ( 0.7 vs. $\left.1.6, p=0.0001^{*}\right)$. D CD19+lympho-

\section{Lymphocyte Subsets}

In alloimmunized patients, the median and $25-75$ percentile (median [25-75 percentile]) values of CD3+, $\mathrm{CD} 4+, \mathrm{CD} 8+$, and $\mathrm{B}$ cells in peripheral blood were expressed as percentage, whereas CD4+ and CD8+ Treg cytes in patients with and without alloantibodies ( 11 vs. $5 \%, p=$ $0.0030^{*}$ ). E CD4+/CD25+/FoxP3+ lymphocytes (TregCD4+) in patients with and without alloantibodies ( 3 vs. 12 cells $/ \mu \mathrm{L}, p=$ $\left.0.0430^{*}\right)$. F CD8+/CD25+/FoxP3+ lymphocytes (TregCD8+) in patients with and without alloantibodies ( 3 vs. 5 cells $/ \mu \mathrm{L}, p=$ $0.5540)$. Mann-Whitney U test statistics, ${ }^{*} p=\leq 0.05$.

cells were expressed as cells/ $\mu \mathrm{L}$ and CD4/CD8 ratio cells. Figure 1 shows dot plots of the acquisition of each lymphocyte subset. Alloimmunized patients had no statistical difference in the percentages of $\mathrm{CD} 3+\mathrm{T}$ lymphocytes compared with the control group (62\% [46-71] vs. $60 \%$ 
[50-74], $p=0.893$ ); but the alloimmunized patients had a lower percentage of CD4+ T lymphocytes compared to the control group (22\% [14-27] vs. 34\% ]29-42], $p=$ 0.0001 ) (Fig. 2A) and a higher percentage of CD8+ T lymphocytes compared to the controls (30\% [20-40] vs. $20 \%$ [18-29], $p=0.003$ ) (Fig. 2B). Inversion in the proportion of CD4+ and CD8+ T lymphocytes (CD4/CD8 ratio) was observed compared to the control group (0.7 [0.5-1.1] vs. $1.6[1.2-2.1], p=0.0001$ ) (Fig. $2 \mathrm{C}$ ). In the alloimmunized patients, a significant increase in the percentage of $\mathrm{B}$ lymphocytes $(\mathrm{CD} 19+)$ was observed compared with the control group (11\% [9-14] vs. 5\% [3-6], $p=0.0053)$ (Fig. 2D). In alloimmunized patients, a significant decrease of regulatory CD4+ T lymphocytes (Treg CD4) was observed in comparison with the control group ( 3 cells/ $\mu \mathrm{L}$ [1-12] vs. 12 cells $/ \mu \mathrm{L}$ [5-17], $p=0.0031$ ) (Fig. $2 \mathrm{E}$ ), while a nonsignificant increase was observed in regulatory CD8+ T lymphocytes (Treg CD8) compared with the control group (3 cells $/ \mu \mathrm{L}[1-20]$ vs. 5 cells/ $\mu \mathrm{L}$ [2-9], $p=0.554$ ) (Fig. 2 F).

\section{Discussion}

The objective of this study was to obtain, as far as possible, a general view of the immunological changes in the alloimmunization process. In this study, the presence and specificity of alloantibodies was determined in patients with transfusion-dependent hematological diseases, as well as the number of B cells, Treg, CD3+, CD4+, CD8+ lymphocytes, and the $\mathrm{CD} 4 / \mathrm{CD} 8$ ratio. In alloimmunized patients, a low number of CD4+ lymphocytes, Treg CD4+ cells, and higher number of $\mathrm{B}$ and $\mathrm{CD} 8+$ lymphocytes was observed in our study, as well as a decrease in the CD4/ CD8 ratio.

We determined the presence and specificity of antierythrocytic alloantibodies in 1,434 transfused hematologic patients, of which only $3.1 \%$ presented positive alloantibodies.

The frequency of antibodies identified in this group of hematological patients is higher than the frequency reported by the Chilean group where they reported that $1.02 \%$ of their study population developed alloantibodies [14]. While another study conducted in Brazilian patients reported a higher frequency (7.5\%) [15]. However, in this study, the results were obtained through a retrospective study performed over more than 6 years, and with a different population sample. Other authors have reported an alloimmunization rate similar to our results, in the range of $3-10 \%$ of recipients in the general population [16].

The prevalence of antibodies reported in studies conducted in Latino population differs according to the country; in this study, we found a higher frequency of nonspecific antibodies (auto anti-IgG), followed by anti-
$\mathrm{Di}^{\mathrm{a}}$ antibodies; whereas in the Chilean and Brazilian population, the prevalence of anti-E antibodies was higher.

Different to the European population, the Latin-American population is more predisposed to alloimmunization with antigens of the Diego system. Even though, in our population, the presence of this erythrocyte antigen was lower. $\mathrm{Di}^{\mathrm{a}}$ is found mainly in populations of Mongolian descent. It is found in $36 \%$ of South American Indians, $12 \%$ of Japanese, and $12 \%$ of Chinese, whereas it is rare in Caucasians and Blacks (0.01\%) [17]. The greater frequency of erythrocyte phenotype in this population is associated with a lower frequency of alloimmunization in this population. Regarding the specificity of antibodies identified by disease, in patients with HA, the predominance of warm IgG autoantibodies and the anti-Rh system is observed, which is consistent with previous reports [18].

MDS, characterized by cytopenias and ineffective hematopoiesis, is usually treated with disease-modifying therapies and supportive care, such as transfusion. In this disease, IgG-specific alloantibodies against RBC antigens were predominantly identified [19].

The processing of antigens is complex, ranging from antigen recognition to development of polyclonal antibodies. In this process, different cell lines intervene; when an erythrocytic alloantigen comes in contact with an antigen-presenting cell (APC-which may be: dendritic cells, macrophages, or B lymphocytes), it must be able to recognize it by using the MHC II molecule; subsequently, it must phagocytose and excise it in small linear peptides that are presented and recognized by a helper CD4+ T lymphocyte or directly by the receptor of B lymphocytes, the latter proliferate and differentiate into plasma cells capable of producing antibodies that will recognize the three-dimensional structure of the presented epitope [20]. In this process, there are several cellular subsets with the ability to develop or inhibit this immunological activity, such as helper $\mathrm{T}$ lymphocytes (T $\mathrm{CD} 4+)$, with costimulatory function, promoting the presentation of linear peptide antigens to $\mathrm{B}$ lymphocytes. Regulatory $\mathrm{T}$ CD4+ lymphocytes produce IL-10 (anti-inflammatory cytokine) that inhibits cellular activation, mainly helper T lymphocytes [21].

The decrease of these regulatory subpopulations has been associated with the development of autoimmune diseases, such as AHAI, in which there is a predominance of autoreactive CD4+ T lymphocytes and production of IgG autoantibodies, which recognize erythrocytic antigens, constituting the pathophysiology of disease. In our study, we observed that in general, all alloimmunized patients had a lower number of CD4+ Treg lymphocytes, even in patients with AHAI, which can be associated with the increased activity of T CD4+ lymphocytes, and with it the greater presentation of erythrocytic alloantigens [22]. 
Another important aspect to consider in the process of presentation of alloantigens and alloimmunization is the variability in the MHC II molecules, since the polymorphisms of HLA-DR have been proposed as a relevant factor alloimmunization, because they depend on the primary recognition capacity of a linear epitope that will culminate with the development of an alloantibody that will recognize the same epitope but three-dimensionally [2325]. One weakness of our study is that this variable was not evaluated, but it is important to emphasize that this is one of the first studies conducted in a Latin population where main lymphoid subsets are evaluated and their number is associated with the alloimmunization process.

In vitro studies report that the main cellular effects of alloimmunization are a decrease in Th1 cytokines and an increase in Th2, as well as an increase in CD8+ T lymphocytes, and a decrease in CD4+ T lymphocytes [26], which is in accordance with our results. It has also been reported that at the beginning of alloimmunization, an increase in the number of CD4+ Tlymphocytes is observed due to an exacerbated antigenic presentation in this period. In patients evaluated in this study, we observed that the group of alloimmunized patients presented a significant decrease in the number of helper CD4+ T lymphocytes, while $\mathrm{CD} 8+\mathrm{T}$ lymphocytes were significantly increased; although the values of leukocytes and total lymphocytes are not different between both groups.

The decrease of CD4+ T lymphocytes has been reported under immunological depletion conditions, as in patients infected with HIV [27], where the antigenic stimulus is constant and for prolonged periods, similar to the immune status of alloimmunized patients. This decrease of CD4+ T lymphocytes is possibly mediated by PD-1/ PDL-1; therefore, inversion of the CD4+/CD8+ proportion and decrease of the $\mathrm{CD} 4 / \mathrm{CD} 8$ ratio are observed.

Two groups of researchers determined separately but simultaneously that the proportion of CD4/CD8 lymphocytes was associated with viral load in patients with HIV, concluding that there is an inverse relation between the CD4/CD8 ratio and viral load, that is, a decrease in viral load and better prognosis. They considered that a CD4/ CD8 ratio of less than 1.0 is an indicator of exhaustion of lymphopoiesis and immunosenescence. Therefore, they proposed that a proportion of CD4/CD8 lymphocytes greater than 1.0 is a favorable prognostic factor for evolution and response to treatment in patients with HIV [28, 29]. In our study, we observed that the non-alloimmunized group had a CD4/CD8 index of 1.6 (percentile 25$75[1.2-2.1])$, while in the group of alloimmunized patients, the index was 0.7 (percentile 25-75 [0.5-1.1]).

Based on the cutoff value referred to in the previously mentioned studies, we consider that a ratio of CD4/CD8 lymphocytes of less than 1.0 could suggest an alloimmunization process, even in cases of evanescence of alloan- tibodies; although it is necessary to conduct more studies to establish it.

In our study, we observed that patients "previously alloimmunized" have a lower media of the CD4/CD8 ratio than patients "not previously alloimmunized" ( 0.8 vs. 1.0 , respectively), possibly due to a greater exposure to erythrocytic alloantigens, and a greater immunological exhaustion. Among the "previously alloimmunized" patients, we found a patient with two alloantibodies. The first anti-C+e specificity was observed at the time of study entry, and the second antibody with anti- $\mathrm{Di}^{\mathrm{a}}$ specificity was identified during follow-up. This patient has also a $\mathrm{CD} 4 / \mathrm{CD} 8$ ratio greater than $1.1($ ratio $=2.2)$, suggesting that the number of CD4+ T lymphocytes is increased, which, according to the reports, is associated to antigenic processing activity and an early stage of the alloimmunization process.

A similar case occurred in the group of "not previously alloimmunized" patients, where we found a patient with a CD4/CD8 ratio equal to 3.3 , in whom two alloantibodies with anti-e and anti-Fy ${ }^{\mathrm{a}}$ specificity were identified. It is known that these alloantibodies are highly immunogenic proteins.

Our group suggests that in the early stages of alloimmunization, the CD4/CD8 ratio is increased; and as the humoral immune response is established and immune exhaustion continues, this value decreases. This finding could be a marker of the occurrence of alloimmunization in transfused patients.

It has been reported that up to $40 \%$ of alloantibodies subsequently become undetectable, especially when patients do not receive transfusion therapy again. In these cases, the $\mathrm{CD} 4 / \mathrm{CD} 8$ ratio can be a useful tool to identify this group of patients [30].

Finally, an important limitation of this study is the number of patients evaluated. Since it was a cross-sectional study, and although 1,434 patients were analyzed, the frequency of alloimmunization is similar to that reported by other studies.

\section{Conclusions}

The most significant immunological alterations observed in alloimmunized patients were the decreased CD4/CD8 ratio, increased B lymphocytes, and Treg lymphocyte deficiency.

\section{Acknowledgments}

This work was supported in part by a grant from SIP-IPN 20160954. R.M.-A. is a fellow of CONACYT (No. 280269) and research fellow IMSS (No. 98366535). E.R.-M. is EDI and COFAA fellow. E.R.-M., L.A.M.-C., and J.V.-O. are SNI fellows. 


\section{Statement of Ethics}

The experiments performed in the present paper complied with the current laws of Mexico and were approved by the Ethical Committee of the Hospital de Alta Especialidad Dr. Antonio Fraga Mouret, Centro Médico Nacional La Raza, Instituto Mexicano del Seguro Social.

\section{Disclosure Statement}

The authors have no potential conflicts of interest to disclose.

\section{References}

1 Malagón-Martínez A. Guía para el uso clínico de la sangre. Tercera edición. México: Secretaría de Salud; 2007. pp. 24-8.

2 Goodnough LT, Panigrahi AK. Blood transfusion therapy. Med Clin North Am. 2017 Mar;101(2):431-47.

3 Gehrie EA, Tormey CA. The influence of clinical and biological factors on transfusion-associated non-ABO antigen alloimmunization: responder, hyper-responders, and nonresponders. Transfus Med Hemother. 2014 Nov;41(6):420-9.

4 Körmöczi GF, Mayr WR. Responder individuality in red blood cell alloimmunization. Transfus Med Hemother. 2014 Nov;41(6): 446-51.

5 Kaur D, Bains L, Kandwal M, Parmar I. Erythrocyte alloimmunization and autoimmunization among blood donors and recipients. J Clin Diagn Res. 2017 Mar;11(3):EC12-5.

6 Philip J, Biswas AK, Hiregoudar S, Kushwaha N. Red blood cell alloimmunization in multitransfused patients in a tertiary care center in Western India. Lab Med. 2014;45(4):324-30.

7 Hendrickson JE, Tormey CA. Red Blood Cell Antibodies in Hematology/Oncology $\mathrm{Pa}$ tients: Interpretation of Immunohematologic Tests and Clinical Significance of Detected Antibodies. Hematol Oncol Clin North Am. 2016 Jun;30(3):635-51.

8 Bhuva DK, Vachhani JH. Red cell alloimmunization in repeatedly transfused patients. Asian J Transfus Sci. 2017 Jul-Dec;11(2):11520.

9 Tormey CA, Stack G. Immunogenicity of blood group antigens: a mathematical model corrected for antibody evanescence with exclusion of naturally occurring and pregnancyrelated antibodies. Blood. 2009 Nov; 114(19): 4279-82.

10 Yazdanbakhsh K. Immunoregulatory networks in sickle cell alloimmunization. Hematology (Am Soc Hematol Educ Program). 2016 Dec;2016(1):457-61.

11 Patel SR, Smith NH, Kapp L, Zimring JC. Mechanisms of alloimmunization and subsequent bone marrow transplantation rejection induced by platelet transfusion in a murine model. Am J Transplant. 2012 May;12(5): 1102-12.
12 Adams B, Dubois A, Delbauve S, Debock I, Lhommé F, Goldman M, et al. Expansion of regulatory $\mathrm{CD} 8+\mathrm{CD} 25+\mathrm{T}$ cells after neonatal alloimmunization. Clin Exp Immunol. 2011 Mar;163(3):354-61.

13 Zahran AM, Elsayh KI, Saad K, Embaby M, Ali AM. Regulatory B cells (CD19(+) CD38(hi)CD24(hi)) in alloimmunized and non-alloimmunized children with $\beta$-thalassemia major. Blood Cells Mol Dis. 2016 Mar;57:91-6.

14 Caamaño J, Musante E, Contreras M, Ulloa $\mathrm{H}$, Reyes C, Inaipil V, et al. Frequency and specificity of red blood cell alloimmunization in chilean transfused patients. Transfus Med Hemother. 2015 Jan;42(1):4-7.

15 Cruz RO, Mota MA, Conti FM, Pereira RA, Kutner JM, Aravechia MG, et al. Prevalence of erythrocyte alloimmunization in polytransfused patients. Einstein (Sao Paulo). 2011 Jun;9(2):173-8.

16 Zimring JC, Hudson KE. Cellular immune responses in red blood cell alloimmunization. Hematology (Am Soc Hematol Educ Program). 2016 Dec;2016(1):452-6.

17 Reid ME, Lomas-Francis C. The Blood Group Antigen Facts Book. 2nd ed. New York: Elsevier Academic Press; 2004.

18 Garratty G. The James Blundell Award Lecture 2007: do we really understand immune red cell destruction? Transfus Med. 2008 Dec; 18(6):321-34

19 Steensma DP. Myelodysplastic syndromes current treatment algorithm 2018. Blood Cancer J. 2018 May;8(5):47.

20 Sippert EÂ, Visentainer JE, Alves HV, Rodrigues C, Gilli SC, Addas-Carvalho M, et al. Red blood cell alloimmunization in patients with sickle cell disease: correlation with HLA and cytokine gene polymorphisms. Transfusion. 2017 Feb;57(2):379-89.

21 Hendrickson JE, Chadwick TE, Roback JD, Hillyer CD, Zimring JC. Inflammation enhances consumption and presentation of transfused RBC antigens by dendritic cells. Blood. 2007 Oct;110(7):2736-43.

22 Ryder AB, Hendrickson JE, Tormey CA. Chronic inflammatory autoimmune disorders are a risk factor for red blood cell alloimmunization. Br J Haematol. 2016 Aug;174(3): 483-5.
23 Hoppe C, Klitz W, Vichinsky E, Styles L. HLA type and risk of alloimmunization in sickle cell disease. Am J Hematol. 2009 Jul;84(7): 462-4.

24 Noizat-Pirenne F, Tournamille C, Bierling P, Roudot-Thoraval F, Le Pennec PY, Rouger P, et al. Relative immunogenicity of Fya and $\mathrm{K}$ antigens in a Caucasian population, based on HLA class II restriction analysis. Transfusion. 2006 Aug;46(8):1328-33.

25 Picard C, Frassati C, Basire A, Buhler S, Galicher V, Ferrera V, et al. Positive association of DRB1 04 and DRB1 15 alleles with Fya immunization in a Southern European population. Transfusion. 2009 Nov;49(11):2412-7.

26 Blumberg N, Heal JM. The transfusion immunomodulation theory: the Th1/Th2 paradigm and an analogy with pregnancy as a unifying mechanism. Semin Hematol. 1996 Oct; 33(4):329-40.

27 Lu W, Mehraj V, Vyboh K, Cao W, Li T, Routy JP. CD4:CD8 ratio as a frontier marker for clinical outcome, immune dysfunction and viral reservoir size in virologically suppressed HIV-positive patients. J Int AIDS Soc. 2015 Jun; 18(1):20052.

28 Serrano-Villar S, Sainz T, Lee SA, Hunt PW, Sinclair E, Shacklett BL, et al. HIV-infected individuals with low CD4/CD8 ratio despite effective antiretroviral therapy exhibit altered T cell subsets, heightened CD8 + T cell activation, and increased risk of non-AIDS morbidity and mortality. PLoS Pathog. 2014 May; 10(5):e1004078.

29 Mussini C, Lorenzini P, Cozzi-Lepri A, Lapadula G, Marchetti G, Nicastri E, et al.; Icona Foundation Study Group. CD4/CD8 ratio normalisation and non-AIDS-related events in individuals with HIV who achieve viral load suppression with antiretroviral therapy: an observational cohort study. Lancet HIV. 2015 Mar;2(3):e98-106.

30 Schonewille H, Haak HL, van Zijl AM. Alloimmunization after blood transfusion in patients with hematologic and oncologic diseases. Transfusion. 1999 Jul;39(7):763-71. 